\title{
ALUNOS DE SHODÔ DO MUNICÍPIO DE SÃO PAULO E SUA PRÁTICA ARTÍSTICA ${ }^{1,2}$
}

\section{Rodrigo Moura Lima de Aragão}

Resumo: Neste artigo, são apresentados e analisados dados referentes a uma parcela dos alunos de shodô do município de São Paulo e dados relacionados à sua prática artística. A partir da aplicação de questionários em oito espaços/associações de São Paulo nos quais o shodô é ensinado, reuniram-se, neste trabalho, os seguintes dados: idade, sexo e nacionalidade dos alunos de shodô das instituições visitadas; nível de conhecimento desses alunos quanto à língua japonesa; tempo de prática de shodô dos respondentes; estilos de shodô praticados por esses alunos; razões pelas quais os alunos das instituições visitadas praticam shodô. Além disso, procedeu-se neste estudo à análise desses dados, a fim de sugerir percursos para o futuro desenvolvimento do shodô em São Paulo.

Palavras-chave: shodô, arte da caligrafia japonesa, ensino de shodô, alunos de shodô, shodô em São Paulo.

Abstract: In this paper, data on part of the shodô students from the city of Sao Paulo and data concerning their artistic practice are presented and analyzed. Based upon a survey conducted at eight different institutions in Sao Paulo where shodo is taught, the following data are gathered in

1. Este artigo apresenta percursos e resultados do projeto de iniciação científica intitulado Panorama das metodologias de ensino da arte da caligrafia japonesa, shodô, no município de São Paulo, o qual foi realizado nos anos de 2006 e 2007 no Centro de Estudos Japoneses da Universidade de São Paulo, sob orientação da professora Dra. Madalena Hashimoto Cordaro e com financiamento do governo da província de Toyama, Japão.

2. Agradece-se, em especial, à professora Dra. Madalena Hashimoto Cordaro, pela orientação primorosa na realização do projeto que deu origem a este artigo; agradece-se, também, aos professores de shodô Soko Ishikawa, Joku Wakamatsu, Shoka Kodera, Nampo Kurachi, Hisae Sagara e Keiko Tada - e a todos os seus alunos -, sem os quais a realização deste trabalho não seria possível; agradece-se, ainda, a Barbara Inagaki, pela revisão da versão em japonês dos questionários formulados, e ao(s) parecerista(s) anônimo(s) da revista Estudos Japoneses, pelas sugestões e apontamentos que permitiram aprimorar este trabalho. 
this work: age, sex, and nationality of the shodô students of the visited institutions; level of knowledge of Japanese of these students; length of practice of shodô of the respondents; styles of shodô practiced by these students; reasons why the students of the visited institutions practice shodô. Moreover, in this paper these data are analyzed, in order to make suggestions for the future development of shodô in Sao Paulo.

Keywords: shodô, the art of Japanese calligraphy, shodô teaching, shodô students, shodô in Sao Paulo.

\section{Introdução}

Decorridos mais de cem anos do início da imigração japonesa no Brasil, algumas das manifestações artísticas e culturais trazidas pelos imigrantes japoneses têm sua prática consolidada no país. São exemplos a arte do arranjo floral, ikebana, o cerimonial do chá, chanoyu, e a arte da caligrafia japonesa, shodô, a qual constitui o foco deste artigo.

Atualmente, a arte da caligrafia japonesa é ensinada em espaços diversos no município de São Paulo, tais como associações de província (kenjinkai) e escolas de língua japonesa. Contudo, pouco se sabe até o momento sobre o ensino dessa arte no que se refere aos seus alunos em São Paulo. Trabalhos anteriores acerca do shodô abordaram essa arte sob uma perspectiva semiótica (SAITO, 2004), refletiram acerca de seu teor artístico (ARAGÃO, 2006) e, quando trataram de seu ensino, centraram-se na análise da produção de um único aprendiz (ARAGÃO, 2007). No que diz respeito aos alunos de shodô em São Paulo, sob um enfoque mais amplo, entretanto, há uma lacuna.

Este artigo dirige-se, justamente, a esse espaço, tendo-se como objetivo, aqui, reunir e analisar dados relacionados aos alunos de shodô em São Paulo. Especificamente, a partir de coleta de dados realizada nesse município, são apresentados, neste trabalho, dados de parte dos alunos de shodô de São Paulo - como faixa etária e nacionalidade - e dados referentes à prática da arte da caligrafia japonesa que é por eles realizada. Além disso, procede-se neste artigo à análise desses dados, a fim de sugerir percursos para o desenvolvimento futuro do shodô em São Paulo.

Este artigo possui a seguinte estrutura: na próxima seção, os métodos de coleta de dados empregados neste estudo são detalhados; depois, em "Associações e Espaços Visitados", abre-se um parêntese para uma breve exposição acerca das instituições nas quais a coleta de dados foi realizada; em "Resultados", os dados obtidos são apresentados na forma de tabelas e gráficos; e, em "Análise dos Resultados", procede-se à análise desses dados, ponderando-se o desenvolvimento do shodô em São Paulo; por último, em "Considerações Finais", apresenta-se uma síntese crítica do que foi feito e expõem-se questões para pesquisas futuras acerca do shodô no âmbito de seu ensino, aprendizado e prática. 


\section{Metodologia de Pesquisa}

Neste estudo, foram visitados entre novembro de 2006 e maio de 2007 oito espaços/associações no município de São Paulo nos quais o shodô é ensinado. São estes: Associação dos Clubes de Anciões do Brasil (Burajiru Nikkei Rôjin Kurabu Rengôkai), Associação Centro Social Ibaraki do Brasil (Burajiru Ibaraki Kenjinkai), Associação de Shodô do Brasil (Burajiru Shodô Aikôkai) ${ }^{3}$. Associação Beneficente Feminina Esperança (Esuperansa Fujinkai), Aliança Cultural Brasil-Japão, Templo Busshinji, Shiinomi Gakuen e Associação Beneficente e Cultural Miyazaki (Burajiru Miyazaki Kenjinkai) ${ }^{4}$. Esses espaços/associações foram selecionados a partir da lista de associações, cursos e professores de shodô apresentada no Guia da cultura japonesa (GUIA, 2004, p. 144-5) e a partir do contato inicial com alguns dos professores de shodô citados nessa lista - foram incluídos no estudo as duas associações e os dois cursos de shodô listados no guia, assim como parte dos espaços/associações que aparecem relacionados a professores de shodô em sua listagem (espaços/associações na maioria das vezes sugeridos pelos professores em um contato inicial).

Ao longo das visitas, foram distribuídos aos alunos questionários em português e japonês que trataram dos seguintes pontos: dados gerais dos alunos (idade, sexo e nacionalidade); nível de conhecimento dos praticantes quanto à leitura, escrita, compreensão auditiva e fala do japonês; tempo de prática de shodô; estilos de shodô praticados; razões pelas quais os alunos praticam shodô.

No total, cento e vinte e dois alunos responderam ao questionário formulado, com a seguinte distribuição no que se refere aos espaços/associações visita$\operatorname{dos}^{5}$ :

3. Aulas ministradas na Associação dos Clubes de Anciões do Brasil.

4. Aulas da associação Aoi Shodô Kai, que aparece no Guia da cultura japonesa (GUIA, 2004, p. 144) com o nome de Nihon Shogakukan do Brasil.

5. Cabe observar que os números apresentados não correspondem estritamente ao total de alunos de shodô das instituições visitadas - o número de respondentes é, na realidade, menor do que o número de alunos de cada instituição (ou porque, no dia da aplicação dos queśtionários, parte dos alunos estava ausente, ou porque uma parcela dos alunos presentes não respondeu ao questionário). 


\begin{tabular}{|c|c|c|}
\hline Espaço/Associação & Número de respondentes (absoluto) & Número relativo $(\%)$ \\
\hline $\begin{array}{c}\text { Associação dos Clubes de Anciões do } \\
\text { Brasil }\end{array}$ & 39 & $31,97 \%$ \\
\hline $\begin{array}{l}\text { Associação Centro Social Ibaraki do } \\
\text { Brasil }\end{array}$ & 19 & $15,57 \%$ \\
\hline Associação de Shodô do Brasil & 22 & $18,03 \%$ \\
\hline $\begin{array}{c}\text { Associação Beneficente Feminina } \\
\text { Esperança }\end{array}$ & 2 & $1,64 \%$ \\
\hline Aliança Cultural Brasil-Japão & 9 & $7,38 \%$ \\
\hline Templo Busshinji & 9 & $7,38 \%$ \\
\hline Shiinomi Gakuen & 18 & $14,75 \%$ \\
\hline $\begin{array}{c}\text { Associação Beneficente e Cultural } \\
\text { Miyazaki }\end{array}$ & 4 & $3,28 \%$ \\
\hline Total & 122 & $100 \%$ \\
\hline
\end{tabular}

Tabela 1. Número (absoluto e relativo) de alunos de shodô que responderam ao questionário formulado em cada um dos espaços/associações visitados.

Embora não se saiba com precisão quantos alunos de shodô há no município de São Paulo, estima-se que o número de respondentes deste estudo corresponda a não menos do que vinte por cento desse total - sabe-se que, em 2004, o número de praticantes de shodô no Brasil chegava "[...] a cerca de quinhentas pessoas" (WAKAMATSU, 2004, p. 83); assim, supondo-se que esse número tenha se mantido relativamente estável até o final de 2006 e início de 2007, e supondo-se que haja uma maior concentração de praticantes de shodô no município de São Paulo em comparação com outras localidades do país, não se considera exagero afirmar que os cento e vinte e dois alunos que participaram da pesquisa correspondem a, pelo menos, vinte por cento do total de alunos de shodô de São Paulo, à época da realização da pesquisa.

A seguir, abre-se um parêntese, fazendo-se uma breve exposição sobre as associações e espaços nos quais os questionários foram distribuídos.

\section{Associações e Espaços Visitados}

A maior parte das associações e espaços visitados tem origem em um período dos nikkeis na sociedade brasileira que é chamado por Harada $(2008$, p. 41) de "etapa da integração ou da busca de uma nova pátria" (de 1942 a 1962): a Associação Beneficente Feminina Esperança e a Assóciação Beneficente e Cultural Miyazaki foram fundadas em 1949 (ESUPERANSA, 2009; MIYAZAKI, 2009) ${ }^{6}$; a escola Shiinomi Gakuen, em 1952 (SÔRITSU, 2009); a instalação do

6. Cabe observar que, no texto citado do jornal Nikkey Shimbun a respeito da Associação Beneficente e Cultural Miyazaki, não consta a informação de que essa associação foi criada em 1949, apenas a de que a associação completou 60 anos em 2009, a partir da qual se deduz o seu ano de fundação. 
Templo Busshinji se deu em 1955 (HISTÓRIA, 2009); a fundação oficial da Aliança Cultural Brasil-Japão ocorreu em 1956 (HARADA, 2008, p. 62); e a Associação Centro Social Ibaraki do Brasil foi fundada em 1961 (TOKUSHÛ, 2006). Nesse período, surge a "[...] idéia de fixação de residência definitiva [...]" dos nikkeis no Brasil (HARADA, 2008, p. 41), sendo possível afirmar que o propósito do estabelecimento dessas instituições provavelmente convergiu com o intuito dos nikkeis de permanecerem no país, talvez com exceção da Associação Beneficente Feminina Esperança, cujo objetivo inicial foi enviar provisões/ mantimentos ("kyûen busshi") ao Japão pós-guerra (ESUPERANSA, 2009).

As demais instituições visitadas, por seu turno, têm história mais breve, com fundação na década de 70 (portanto, em um contexto social e histórico diferente): a Associação dos Clubes de Anciões do Brasil foi fundada em 1975, tendo como objetivos promover uma vida plena aos idosos nikkeis que vivem no país e "[...] planejar as medidas necessárias às atividades dos clubes de anciões" (RÔJIN, 2005, tradução nossa) $)^{7}$; já a Associação de Shodô do Brasil foi criada em 1979, tendo como impulso a exposição de shodô que ocorreu no Museu de Arte de São Paulo Assis Chateaubriand (MASP) no ano de 1975 (WAKAMATSU, 2004). Com relação ao período de fundação dessas instituições, Harada $(2008$, p. 43) afirma que o nikkei, integrado à sociedade brasileira, partilha com esta sua cultura; contudo, assinala ainda que ele, "[...] em seus momentos de intimidade, prefere buscar o aconchego do seu lar cultural" Enquanto a Associação dos Clubes de Anciões do Brasil parece proporcionar aos nikkeis ainda hoje esse aconchego, avalia-se que a Associação de Shodô do Brasil constituiu-se em um meio de partilha da riqueza cultural japonesa, sobretudo pelo papel relevante que vem desempenhando na divulgação do shodô no Brasil.

No que diz respeito ao ensino de shodô, observou-se um enfoque diferente em cada uma das instituições visitadas. Na Associação dos Clubes de Anciões do Brasil, por exemplo, parece haver um maior apelo aos benefícios da arte da caligrafia japonesa para a saúde física e mental dos praticantes. Já na escola Shiinomi Gakuen, notou-se uma maior ênfase na faceta do shodô como exercício da escrita japonesa e, também, como atividade recreativa. Nas aulas da Associação de Shodô do Brasil, por sua vez, o caráter artístico do shodô, a expressão da individualidade por meio dos traços e do uso do espaço, parece receber mais atenção. Ainda que, em todas as instituições visitadas, o shodô enquanto arte, o shodô enquanto exercício da escrita, o shodô enquanto elemento da cultura japonesa e suas demais faces sejam, sim, trabalhadas, observou-se uma maior ênfase na transmissão e desenvolvimento de uma ou outra face do shodô em cada uma das instituições. Em alguns casos, o fator determinante para isso parece ser o público, os aprendi-

7. Objetivos do texto original, em japonês: "Mokuteki: Burajiru zaijû nikkei zaitaku kôreisha no rôgo seikatsu jûjitsu wo mokuteki to suru, rôjin kurabu katsudô ni hitsuyô na bengi wo hakaru koto" (RÔJIN, 2005). 
zes; em outros, a postura do professor diante do shodô é aparentemente o que confere à abordagem uma ou outra tonalidade. sentados.

A seguir, os resultados da coleta de dados realizada neste estudo são apre-

\section{Resultados}

As respostas dadas pelos alunos de shodô das associações e espaços visitados foram agrupadas nas tabelas e gráficos desta seção. A tabela 2 apresenta a proporção de alunos homens e mulheres (números absoluto e relativo); a tabela 3, a faixa etária dos alunos de shodô (números absoluto e relativo); a tabela 4 reúne dados referentes à nacionalidade dos respondentes (números absoluto e relativo); já a tabela 5 apresenta o número (absoluto e relativo) de alunos de shodô brasileiros com ascendência japonesa, naturalizados e sem ascendência japonesa.

\begin{tabular}{|c|c|c|}
\hline Sexo & Número de alunos (absoluto) & Número relativo (\%) \\
\hline Masculino & 39 & $31,97 \%$ \\
\hline Feminino & 82 & $67,21 \%$ \\
\hline Não responderam & 1 & $0,82 \%$ \\
\hline Total & 122 & $100 \%$ \\
\hline
\end{tabular}

Tabela 2. Proporção de homens e mulheres dos alunos de shodô das instituições visitadas (números absoluto e relativo).

\begin{tabular}{|c|c|c|}
\hline Faixa etária & Número de alunos (absoluto) & Número relativo (\%) \\
\hline Abaixo de 20 anos & 18 & $14,75 \%$ \\
\hline Entre 20 e 40 anos & 8 & $6,56 \%$ \\
\hline Entre 40 e 60 anos & 11 & $9,02 \%$ \\
\hline Acima de 60 anos & 81 & $66,39 \%$ \\
\hline Não responderam & 4 & $3,28 \%$ \\
\hline Total & 122 & $100 \%$ \\
\hline
\end{tabular}

Tabela 3. Faixa etária dos alunos de shodô das instituições visitadas (números absoluto e relativo).

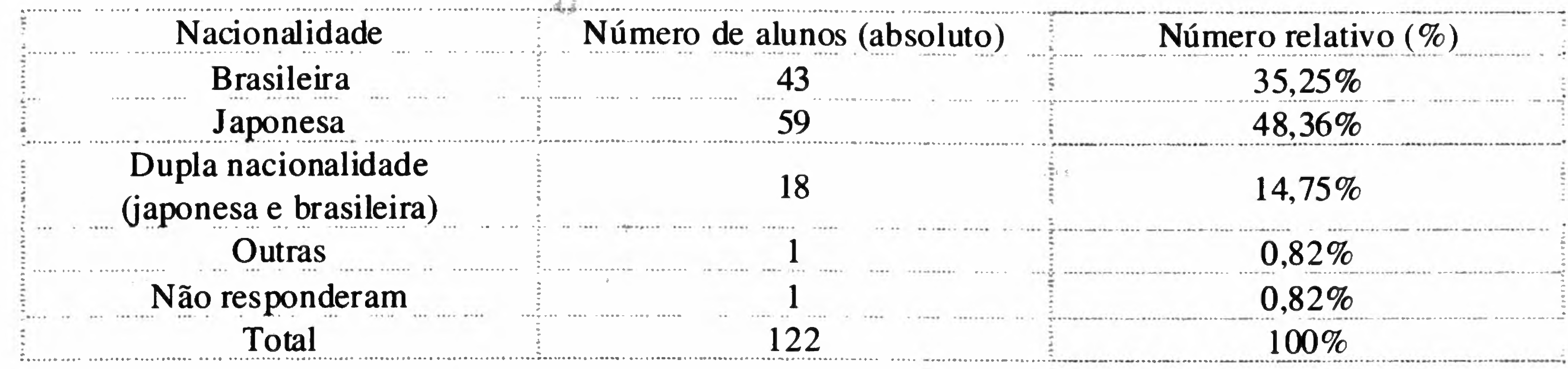

Tabela 4. Nacionalidade dos alunos de shodô das instituições visitadas (números absoluto e relativo). 
Ascendência/Origem

Ascendência japonesa (nisei)

Ascendência japonesa (sansei)

Naturalizado (orige m japonesa)

Sem ascendência japonesa

Total

\section{Número de alunos (absoluto)}

24

12

1

43
Número relativo $(\%)$

$55,81 \%$

$27,91 \%$

$2,33 \%$

$13,95 \%$

$100 \%$

Tabela 5. Número (absoluto e relativo) de alunos de shodô brasileiros com ascendência japonesa, naturalizados e sem ascendência japonesa que participaram do estudo.

As tabelas 6, 7, 8 e 9, por sua vez, apresentam a auto-avaliação dos alunos das instituições visitadas quanto ao conhecimento de língua japonesa no que se refere, respectivamente, à leitura, escrita, compreensão auditiva e fala do idioma (números absolutos e relativos).

\begin{tabular}{c|ccc} 
Nivel de conhecimento (leitura) & Número de alunos (absoluto) & Número relativo $(\%)$ \\
Nenhum & 4 & 19 & $3,28 \%$ \\
Pouco & 32 & $15,57 \%$ \\
Razoável & 48 & 19 & $26,23 \%$ \\
Bom & 122 & $39,34 \%$ \\
Ótimo & $15,57 \%$ \\
Total & $100 \%$ & 1 \\
\hline
\end{tabular}

Tabela 6. Auto-avaliação dos alunos de shodô das instituições visitadas do nível de conhecimento da língua japonesa quanto à leitura (números absoluto e relativo).

\begin{tabular}{|c|c|c|}
\hline Nível de conhecimento (escrita) & Número de alunos (absoluto) & Número relativo $(\%)$ \\
\hline Nenhum & 4 & $3,28 \%$ \\
\hline Pouco & 20 & $16,39 \%$ \\
\hline Razoável & 31 & $25,41 \%$ \\
\hline Bom & 46 & $37,7 \%$ \\
\hline Ótimo & 18 & $14,75 \%$ \\
\hline Não responderam / Inválidos & 3 & $2,46 \%$ \\
\hline Total & 122 & $100 \%$ \\
\hline
\end{tabular}

Tabela 7. Auto-avaliação dos alunos de shodô das instituições visitadas do nível de conhecimento da língua japonesa quanto à escrita (números absoluto e relativo). 


\begin{tabular}{|c|c|c|c|}
\hline $\begin{array}{c}\text { Nível de conhecimento } \\
\text { (compreensão auditiva) }\end{array}$ & Número de alunos (absoluto) & Número relativo (\%) \\
\hline Nenhum & 4 & $3,28 \%$ \\
\hline Pouco & 14 & 29 & $11,48 \%$ \\
\hline Razoável & 46 & $23,77 \%$ \\
\hline Bom & 24 & 5 & $37,7 \%$ \\
\hline Ótimo & 122 & $19,67 \%$ \\
\hline Náo responderam / Inválidos & & $4,1 \%$ \\
\hline Total & & $100 \%$ \\
\hline
\end{tabular}

Tabela 8. Auto-avaliação dos alunos de shodô das instituições visitadas do nível de conhecimento da língua japonesa quanto à compreensão auditiva (números absoluto e relativo).

\begin{tabular}{|c|c|c|}
\hline Nível de conhecimento (fala) & Número de alunos (absoluto) & Número relativo (\%) \\
Nenhum & 6 & $4,92 \%$ \\
\hline Pouco & 20 & $16,39 \%$ \\
\hline Razoável & 25 & $20,49 \%$ \\
\hline Bom & 49 & $40,16 \%$ \\
\hline Ótimo & 18 & $14,75 \%$ \\
\hline Não responderam / Inválidos & 4 & $3,28 \%$ \\
\hline Total & 122 & $100 \%$ \\
\hline
\end{tabular}

Tabela 9. Auto-avaliação dos alunos de shodô das instituições visitadas do nível de conhecimento da língua japonesa quanto à fala (números absoluto e relativo).

Já a tabela 10 apresenta o tempo de prática de shodô informado pelos respondentes (número de alunos absoluto e relativo); e a tabela 11, o número (absoluto e relativo) de alunos das instituições visitadas que informaram praticar cada um dos estilos de shodô desenvolvidos no município de São Paulo, isto é, kaisho (escrita padrão ou de fôrma), gyôsho (escrita semi-cursiva), sôsho (escrita cursiva), kana, reisho (escrita clerical), tensho (escrita de selos), tenkoku (entalhadura de selos), kôhitsu ("pincel rígido" estilo executado com caneta esferográfica), ichijisho (escrita de um caractere), kindaishibunsho (escrita de poesia moderna), zen'eisho (escrita de vanguarda) e kokuji ("letra entalhada").

8. Foge do escopo deste trabalho a descrição pormenorizada de cada um desses estilos e, portanto, limita-se aqui à sua menção e tradução simples. Para uma visão geral dos principais estilos de shodô, são sugeridos os trabalhos de Nakata (1983) e Wakamatsu (2004). 


\begin{tabular}{|c|c|c|}
\hline Tempo de prática & Número de alunos (absoluto) & Número relativo (\%) \\
\hline Mais de 10 anos & 17 & $13,93 \%$ \\
\hline Entre 5 e 10 anos & 24 & $19,67 \%$ \\
\hline Entre 2 e 5 anos & 24 & $19,67 \%$ \\
\hline Entre 6 meses e 2 anos & 32 & $26,23 \%$ \\
\hline Menos de 6 meses & 17 & $13,93 \%$ \\
\hline Não responderam & 8 & $6,56 \%$ \\
\hline Total & 122 & $100 \%$ \\
\hline
\end{tabular}

Tabela 10. Tempo de prática de shodô assinalado pelos respondentes (número de alunos absoluto e relativo).

\begin{tabular}{|c|c|c|}
\hline Estilo praticado & Número de alunos (absoluto) & Número relativo $(\%)$ \\
\hline Kaisho & 89 & $72,95 \%$ \\
\hline Gyôsho & 70 & $57,38 \%$ \\
\hline Kana & 65 & $53,28 \%$ \\
\hline Sôsho & 48 & $39,34 \%$ \\
\hline Kôhitsu & 33 & $27,05 \%$ \\
\hline Ichijisho & 32 & $26,23 \%$ \\
\hline Reisho & 30 & $24,59 \%$ \\
\hline Tensho & 22 & $18,03 \%$ \\
\hline Kindaishibunsho & 16 & $13,11 \%$ \\
\hline Kokuji & 11 & $9,02 \%$ \\
\hline Tenkoku & 5 & $4,1 \%$ \\
\hline Zen'eisho & 3 & $2,46 \%$ \\
\hline
\end{tabular}

Tabela 11. Número (absoluto e relativo) de alunos que participaram do estudo para cada um dos estilos de shodô desenvolvidos no município de São Paulo.

Por último, o gráfico 1 reúne as razões mais freqüentes apresentadas pelos alunos de shodô que participaram da pesquisa para a prática dessa arte (total de dez razões). 


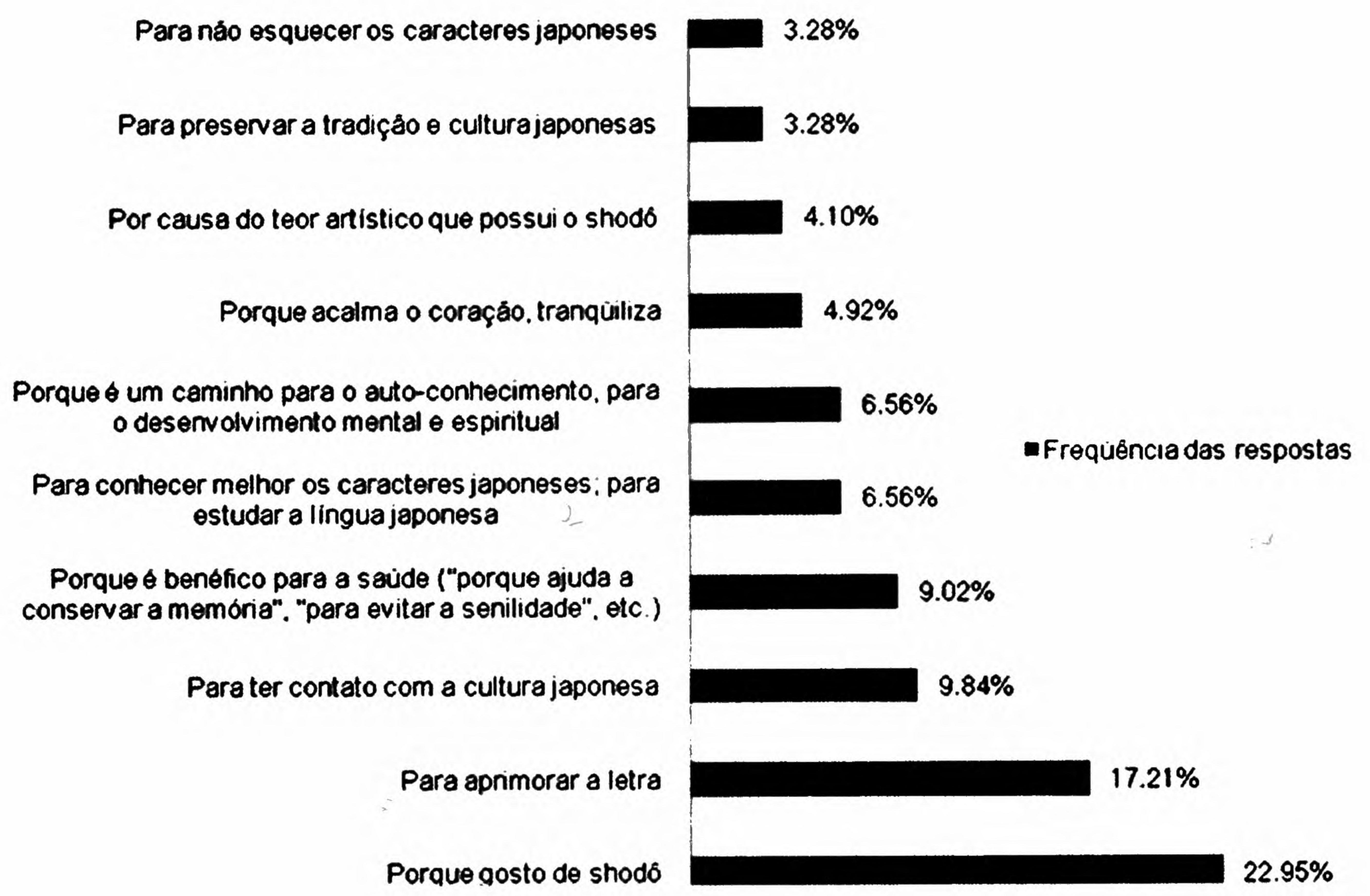

Gráfico 1. Dez razões mais freqüentes apresentadas pelos respondentes para a prática do shodô.

A seguir, procede-se à análise dos resultados apresentados nesta seção.

\section{Análise dos Resultados}

A análise dos resultados obtidos neste estudo está organizada em duas subseções: 1) Perfil dos alunos de shodô do município de São Paulo; 2) Prática de shodô no município de São Paulo. Em cada uma dessas subseções, procede-se à síntese dos resultados apresentados nas tabelas e no gráfico da seção anterior e à análise desses resultados, ponderando-se o seu significado para o desenvolvimento futuro do shodô em São Paulo.

1) Perfil dos alunos de shodô do município de São Paulo

A partir das tabelas 2, 3, 4 e 5, verifica-se que: (1) a maior parte dos alunos de shodô $(67,21 \%)$ que participaram da pesquisa é composta por mulheres; (2) a maior parte desses alunos (66,39\%) tem idade superior a 60 anos; (3) aproximadamente metade dos alunos de shodô $(48,36 \%)$ que responderam ao questionário é de nacionalidade japonesa; (4) entre os respondentes de nacionalidade brasi- 
leira, a porcentagem de alunos sem ascendência japonesa corresponde a uma pequena parcela $(13,95 \%)$ apenas.

Com relação a esses dados, considera-se relevante o fato de que o shodô parece manter-se como uma prática quase restrita à comunidade nipo-brasileira em São Paulo, e aponta-se a necessidade de que seja buscada uma maior difusão do shodô além dos limites dessa comunidade. Avalia-se que estender os horizontes do shodô em São Paulo consista em um passo importante para o desenvolvimento dessa arte no município, tanto porque essa extensão pode somar perspectivas artísticas várias ao shodô - uma vez que indivíduos com repertórios culturais mais diversificados integrariam sua prática -, como porque pode ter um papel fundamental na continuidade do crescimento do shodô em São Paulo. Se, por um lado, a prática do shodô já está consolidada nesse município, por outro, é necessário ponderar o futuro dessa arte em uma sociedade que não é mais o destino de grandes números de imigrantes japoneses, isto é, uma sociedade cujo número de japoneses tende a diminuir e cuja integração de seus descendentes tende a ser cada vez mais acentuada - possivelmente fragilizando o vínculo destes com as manifestações artísticas e culturais japonesas.

Já a partir dos resultados das tabelas $6,7,8$ e 9, verifica-se que, tanto no que diz respeito à leitura, como quanto à escrita, compreensão auditiva e fala do japonês, as maiores proporções de respostas correspondem às avaliações "razoável" e "bom" do conhecimento do idioma. Verifica-se, ainda, uma presença reduzida de alunos que avaliaram o seu conhecimento de japonês como inexistente ("nenhum") em qualquer uma das quatro habilidades e uma proporção que varia entre 11 e $20 \%$ de alunos no que diz respeito às avaliações "pouco" ou "ótimo" do nível de conhecimento da língua japonesa (leitura, escrita, compreensão auditiva e fala).

Esses dados sugerem a existência de uma parcela reduzida de praticantes de shodô que não apresentam qualquer conhecimento da língua japonesa no município de São Paulo, o que, por sua vez, dá a entender que a opção pelo shodô e seu aprendizado possa ter uma relação importante com o repertório de japonês do indivíduo. Embora seja possível desenvolver a caligrafia artística com um distanciamento semântico, praticantes que optam pelo shodô sem nenhuma base da língua japonesa parecem ser minoria em São Paulo.

Contudo, se uma maior difusão do shodô, sobretudo fora da comunidade nipo-brasileira, for visada em São Paulo, faz-se necessário, então, refletir também sobre meios para desenvolver essa arte independentemente do repertório de japonês do indivíduo. Com relação a isso, entende-se que duas seriam as alternativas possíveis. A primeira seria focar o ensino de shodô para alunos sem base em língua japonesa ou no desenvolvimento artístico do sistema de escrita romano, ou em estilos que permitem ao aluno maior liberdade com relação à forma. Já a segunda alternativa seria a composição de material didático dirigido a alunos sem 
conhecimento do japonês, escrito em português, no qual fossem apresentadas ordem e características dos traços, leitura e significado dos ideogramas.

\section{2) Prática de shodô no município de São Paulo}

A partir da tabela 10, verifica-se que a maior parte dos alunos de shodô que participaram da pesquisa assinalou um tempo de prática dessa arte superior a 6 meses e inferior a 10 anos: enquanto as proporções de alunos que praticam shodô há menos de 6 meses e há mais de 10 anos correspondem, ambas, a 13,93\%, as proporções de alunos que praticam shodô há um intervalo entre 6 meses e 2 anos, 2 e 5 anos e 5 e 10 anos correspondem, respectivamente, a $26,23 \%, 19,67 \%$ e $19,67 \%$.

Esses dados sugerem que a prática de shodô no município de São Paulo caracteriza-se, de uma forma geral, como de médio (ou longo) prazo.

Já a partir da tabela 11, verifica-se que: (1) os estilos mais praticados pelos alunos de shodô que participaram do estudo são kaisho (72,95\%), gyôsho $(57,38 \%)$, kana $(53,28 \%)$ e sôsho $(39,34 \%)$; (2) os estilos menos praticados por esses alunos são kindaishibunsho (13,11\%), kokuji $(9,02 \%)$, tenkoku $(4,1 \%)$ e zen'eisho $(2,46 \%)$.

A partir desses dados, pode-se afirmar, primeiro, que o ensino de shodô em São Paulo privilegia a base dessa arte. O kaisho, "[...] comparável em função e sentimento às maiúsculas de fôrma da escrita romana [...]", é a “[...] forma básica do kanji [...]" (NAKATA, 1983, p. 83, tradução nossa) ${ }^{9}$ e constitui a "[...] escrita padrão para iniciantes, pois ensina o uso apropriado do pincel" (SAITO, 2004, p. $20)^{10}$. Ainda, gyôsho e sôsho são também estilos de caligrafia apontados como básicos - cf. Nakata (1983) e Saito (2004) -, sendo o primeiro "[...] um estilo mediano, de letra cursiva, que não se apresenta tão duro quanto o kaisho", e o segundo “[...] um estilo fluido composto por cursos rápidos" (SAITO, 2004, p. 19).

Em segundo lugar, pode-se afirmar, a partir dos dados acima, que o ensino de shodô em São Paulo dá grande ênfase também ao estilo de caligrafia que é próprio ao Japão, isto é, ao $k a n a^{11}$. A alta porcentagem de alunos que informaram praticar esse estilo permite interpretar ainda que talvez seja grande a busca pelo

9. Passagem original em inglês, da qual foram extraídos os fragmentos entre aspas: "Kaisho-in many ways comparable in function and feeling to block capitals in Roman script-is the basic form of kanji and its most important use is as an easily legible workaday style" (NAKATA, 1983, p. 83).

10. Cabe observar que o kaisho é ainda foco do ensino do kanji nas escolas japonesas, desde o shôgakkô (ensino primário japonês) até o kôtôgakkô (ensino secundário/médio japonês) (ZENKOKU DAIGAKU SHOSHA KYÔIKU GAKKAI, 2003, p. 99).

11. Diferentemente do kaisho, gyôsho e sôsho, originários da China, o kana foi desenvolvido no Japão - cf. Nakata (1983). 
padrão de beleza (ou arte) tipicamente japonês na escrita entre os alunos de shodô de São Paulo e, partindo-se desse raciocínio, avalia-se que o kana possui um grande potencial para divulgar a arte da caligrafia japonesa no município, seja para o público geral, seja para futuros praticantes e artistas - acredita-se que peças escritas em kana, por sua beleza e leveza únicas, caracteristicamente japonesas, tenham um poder especial para despertar o interesse das pessoas pelo shodô.

Além disso, os dados sobre os estilos de shodô sugerem uma menor difusão de estilos modernos ou menos convencionais, como o kindaishibunsho e o kokuji, no município de São Paulo. Com relação a isso, entende-se que, apesar de o desenvolvimento da base e do kana ser essencial para uma propagação consistente do shodô em São Paulo, paralelamente, dar ênfase ao moderno, ao novo, e ao menos convencional é também um passo importante para o desenvolvimento dessa arte no munícipio. Isso porque o trabalho com o novo ou menos convencional constitui uma alternativa saliente para a composição de um shodô com características distintas, próprias ao circuito artístico local, que pode tornar ainda mais forte essa arte em São Paulo. Embora inovar em estilos com padrões já bastante sedimentados e convencionais como o kaisho e o gyôsho seja possível, considera-se menor a exeqüibilidade de um objetivo como esse e, assim, defendese a importância de uma maior propagação dos estilos modernos ou menos convencionais da arte da caligrafia japonesa em São Paulo.

Por último, o gráfico 1 reúne as respostas mais freqüentes apresentadas pelos alunos de shodô que participaram da pesquisa para a pergunta: "Por que você está aprendendo shodô?" Essas respostas sinalizam simplicidade na busca pela arte da caligrafia japonesa ("Porque gosto de shodô") e, ainda, evidenciam formas como o shodô é percebido pelos alunos: como um exercício para o aprimoramento da escrita, como uma manifestação da cultura japonesa, como arte, como uma forma de estudo do japonês, como um meio para preservar a saúde e como um caminho para o auto-conhecimento ou desenvolvimento mental e espiritual.

Entende-se que essas percepções acerca da arte da caligrafia japonesa possam ser relevantes, principalmente, para uma maior difusão do shodô em São Paulo. Acredita-se que a exposição do teor artístico do shodô ou dos benefícios que este traz para o praticante, por exemplo, possa ser útil para despertar o interesse de pessoas que buscam ou arte, ou meios para se tornarem mais tranqüilas no cotidiano. Considera-se, pois, que a exploração dessas diferentes perspectivas possa constituir um meio valioso para propagar a arte da caligrafia japonesa no município de São Paulo.

Ademais, entende-se que a compreensão dessas várias faces do shodô possa ser importante também para o professor de caligrafia. Se cabe a ele moldar o ensino aos motivos que impulsionam o aprendizado de seus alunos, para tanto, primeiro, é necessário saber que motivos são esses, e as respostas apresentadas no 
gráfico 1 proporcionam uma visão geral das motivações que levam ao aprendizado do shodô. Ter consciência, por exemplo, de que assim como há alunos que buscam arte, há alunos que buscam um exercício para a escrita, é o primeiro passo para adaptar as aulas aos objetivos dos alunos, buscando a sublimação do indivíduo e sua obra ao patamar de artista e arte, quando for o caso, ou procurando promover a fixação da ordem, direção e forma dos traços dos ideogramas, quando esta for a motivação do aprendiz.

A seguir, breves considerações encerram o artigo.

\section{Considerações Finais}

Neste estudo, foram apresentados e analisados dados referentes a uma parcela dos alunos de shodô do município de São Paulo e dados referentes à sua prática artística. Compôs-se um retrato do ensino de shodô em São Paulo no que diz respeito aos alunos dessa arte e sugeriram-se percursos para o desenvolvimento futuro do shodô em São Paulo.

Avalia-se que os dados apresentados neste artigo são representativos do total de alunos de shodô do município, em decorrência do alto número de respondentes e da diversidade das instituições visitadas. Assinala-se, contudo, que este trabalho não substitui a necessidade de realização de um censo, caso se pretenda obter um quadro mais preciso dos alunos de shodô de São Paulo.

Por último, questões que, entende-se, podem ser consideradas para pesquisas futuras acerca do shodô no âmbito de seu ensino, aprendizagem e prática são as seguintes: "De que forma alunos sem conhecimento de língua japonesa desenvolvem o shodô?", "Há relação entre os estilos de shodô escolhidos pelos alunos e seus objetivos pessoais de aprendizado?" "Quão eficaz é a prática do shodô para o estudo da escrita japonesa?" e "Quais benefícios a prática do shodô traz, de fato, para a saúde de seus praticantes?"

\section{Referências bibliográficas}

ARAGÃO, Rodrigo Moura Lima de. Sobre shodô, Aristóteles e arte. In: AJZENBERG, Elza (Org.). Arteconhecimento (desdobramento do IV Congresso de Estética e História da Arte). São Paulo: MAC-USP/Programa Interunidades de Pós-Graduação em Estética e História da Arte, 2006. 402 p. p. 301-306.

ARAGÃO, Rodrigo Moura Lima de. Um estudo sobre o ensino de shodô a partir de manuscritos. Revista Brasileira de Estudos Pedagógicos, Brasília, v. 88, n. 218, p. 11-29, jan./ abr. 2007.

ESUPERANSA Fujinkai "Kanreki" ni = sengo no fujinkai no sakigake = hakuai no kokoro de ayunda 60 nen. Nikkey Shimbun, São Paulo, 15 ago. 2009. Disponível em: <http:// www.nikkeyshimbun.com.br/090815-71 colonia.html>. Acesso em: 18 jan. 2010. 
GUIA da cultura japonesa. São Paulo: JBC, 2004. 610 p.

HARADA, Kiyoshi. O processo de evolução e de integração dos nikkeis. In: HARADA, Kiyoshi (Coord.). O nikkei no Brasil. São Paulo: Atlas, 2008. 630 p. p. 35-95.

HISTÓRIA. Templo Busshinji (Comunidade Budista Soto Zenshu da América do Sul). Disponível em: <http://www.sotozen.org.br/templo.php>. Acesso em: 18 jan. 2010.

MIYAZAKI Kenjinkai sôritsu 60 shûnen iwau = Higashikokubaru kenchiji, gichô ra mukae = "Burajiru to no kizuna tsuyometai" = USP to Miyazaki daino kyôtei mo. Nikkey Shimbun, São Paulo, 25 ago. 2009. Disponível em: <http://www.nikkeyshimbun.com.br/09082571 colonia.html>. Acesso em: 18 jan. 2010.

NAKATA, Yujiro. The Art of Japanese Calligraphy (The Heibonsha Survey of Japanese ArtVolume 27). Tradução de Alan Woodhull e Armins Nikovskis. Tokyo: Heibonsha, 1983. $172 \mathrm{p}$.

RÔJIN kurabu rengôkai ni tsuite. Imin hyaku nen sai, 5 abr. 2005. Disponível em: <http:// www.100nen.com.br/ja/roukuren/000091/20050405000969.cfm>. Acesso em: 18 jan. 2010.

SAITO, Cecília Noriko Ito. O shodô, o corpo e os novos processos de significação. São Paulo: Annablume, 2004. 78 p.

SÔRITSU 57 nenme no Shiinomi Gakuen = seiichi = kotoshi mo dentô no "shôgatsushiki" = 30 nin tsudoi shinnen iwau = "hitori ni nattemo tsuzuketai" Nikkey Shimbun, São Paulo, 1 ago. 2009. Disponível em: < http://www.nikkeyshimbun.com.br/09010871 colonia.html>. Acesso em: 18 jan. 2010.

TOKUSHÛ Burajiru Ibaraki Kenjinkai sôritsu 45 shûnen. Nikkey Shimbun, São Paulo, 22 ago. 2006. Disponível em: <http://www.nikkeyshimbun.com.br/Tokusyu-ibaragi. html>. Acesso em: 18 jan. 2010.

WAKAMATSU, Joku. Shodo: caligrafia. In: OTA, Junko et al. Dô - A essência da cultura japonesa. São Paulo: Chado Urasenke do Brasil, 2004. p. 68-83.

ZENKOKU DAIGAKU SHOSHA KYÔIKU GAKKAI. Shinpen shosha shidô. Tokyo: Kayahara Shobô, 2003. 168 p. 